\title{
Digital Interaction on Eco Label Value Chain
}

\author{
George Bogdan Dragan \\ bogdan.dragan@ugal.ro \\ Gianita Bleoju \\ gianita.bleoju@ugal.ro \\ Dunarea de Jos University of Galati, Romania
}

\begin{abstract}
The main aim of the paper is to expose the state of the art with methodological analysis conducted on digital interaction within online eco labelling value chain. The return on conceptual and experimental experience involves communities of European eco-label on-line retailers to deepen our knowledge about virtual configurations of sharing access to valuable information. The multiple case studies build upon collaborative experience within eco label chain to enlist strategic options about virtual platform of knowledge exchange. Various concerns arise when it comes to enable collective access to sharing eco retailer interaction with own customers due to cultural approach to openness and exposure to risk of shrinking future purchases. Virtual platform design has to facilitate open access to collaborative learning, making sense of digital interaction to discover patterns of future eco purchase behaviour among each company narrative. In the attempt to assist decision makers to interpret the perceived threats, cultural facilitators have to be explored to raise the awareness on eco retailing partnership about the benefits of variety in exploiting digital interaction return on experience. Companies needs guiding with understanding differences in trustfulness and exposure to risk of engaging in collectively sharing company experience in exchange of discovering future eco purchasing profile. Online retailing markets landscape of experimental learning will employ scenarios of matching eco purchasing profiling and retailer's strategic options about eco future purchase behaviour. The main challenge to face on eco retailing business model concerns how to collectively employ predictive analytics tools to leverage customers' eco behaviour propensity, while shaping own marketing intelligence tools to match eco value based engagement will strengthen each player's competitive response. The digital interaction business model on eco label value chain provides facilitators of exposing marketing experience of each retailer in order to collectively engage in shaping and delivering customer experience to influence value based purchasing.
\end{abstract}

Key words: value based marketing, eco retailing profiling, digital marketing business model, eco-label competitive identity

\section{Value based marketing with eco-label competitive identity}

European eco-retail firms, as well as the few in Romania, have become particularly attractive targets for customers concerned about the origin of products and raw materials, when choosing to make responsible purchases. Digital marketing provides opportunities to gain insights about a disruptive behaviour in shifting from sustainability through moderators as quality of services and the price level toward the value of customer interaction. Furthermore, business practices have to be challenged to shape partnerships with first movers on eco retailing, as many of them are behaving as trend setter in the industry.

Among managerial difficulties to adjust non digital business models to digital environment of enacting skills, of outmost importance is to recognize the opportunity to adjust to emergent colaborative culture behaviour through engaging in goal congruency partnerships moderated by invisible assets coordination mechanisms (Schoemaker, 1993).

Latest case studies accounts about how to recognize barriers and enablers of engaging in eco behaviour driven by various incentives, in the context of eco-label competitive identity emergence, while on line retailing proves difficulties to align eco-label identity and value based marketing. Acknowledging the recent attempts to highlight the digital environment as source of 
producing own knowledge, the research team informs about how reported findings in various cases converge to common difficulties with proving the eco retailing label purpose.

In the attempt to building the bridge, eco-label competitive identity complies with significant changes in eco retailing business practices, while featuring invisible assets coordination, collaborative eco-culture and managing contexts of experiential learning as admissible antecedents to be coherently anchored in the context of holistically approach to Human Centered Design principles.

The conceptual research relies upon the configurational analysis legitimacy to bridge value based competition and business ethics, while mapping a variety of influences driving digital market positioning within on line retailing value chains. The eco oriented environment of interactions is moderated by technology trustfulness; consistent with disruptive technology adoption, while resistance to change is still manifesting, when it comes about disruptive behaviour. Therefore, matching value based marketing and eco-label identity goes beyond common proficiency in exploiting digital marketing tools, toward engaging in disruptive behaviour with experimenting significant changes in business practices to advocate for eco label competitive identity.

Facing increasing complexity about unanticipated future opportunities and threats, digital business models should inquire about how corporate culture profile integrates new features of value based competition while observing business ethics requirements, the former of outmost importance among on line eco sensitive customers. Furthermore, to maximize the impact of the adopted eco behavior driven positioning, in the context of digital strategic assets modeling, eco corporate culture should set up green empathy alert tools, enacting as bias interrupters while staying vigilant about proactivity and delivering complementarily features.

The digital interaction business model on eco label value chain has to setup a virtual platform provides facilitators of exposing marketing experience of each retailer in order to collectively engage in shaping and delivering customer experience to influence value based purchasing.

\section{Literature review}

The customer value creation chain in the European eco-label product industry implies developing smart collaboration between the manufacturers and retailers involved in this field.

New information and communication technologies accelerate the expansion of European producers and retailers of eco-label products in the e-business environment, altering patterns of competitions and generating new sources for the sustainable development of their businesses. Products certified with EU eco-label must comply with the environmental requirements for each stage of production.

Rooted on theory of planned behavior, the importance of promoting the culture of a common learning objective on the value creation chain through the exchange of strategic knowledge between producers, retailers and customers (Chen \& All, 2009) leads to the need to develop a virtual community of collaboration between stakeholders of eco-label products. Customers will have the opportunity of direct interaction, intermediated by the online platform they offer, with both producers and retailers of eco-label products.

The methodological relevance of the collaborative learning approach is consistent with the stakeholder commitment of eco-label products to pooling strategic resources that lead to the optimization of relationships on the value creation chain (Battistella et al., 2015)

Recognizing digital age's challenge upon Human centered design HCD this study staging accounts to the emerging research agenda grounded in making sense of digital technology usability and usefulness through highlighting participatory design impact over human quality of life( G. Fisher 2018).

Changes in practices, such as greening the company's product portfolio, implementing environmental management systems, installing eco-efficient technologies, etc., are therefore considered in the study presented herein (Muñoz, R. M.,2015). 
Cultural diversity is paramount in international markets, while intercultural coordination has the opportunity to take a leadership role in re-shaping management research as a whole toward greater integration between theory and practice, thus making our field more scientifically rigorous and practically relevant(Cheng, J. L. ,2007).

The findings of a research conducted by Kim and Lee (2012) provide empirical evidence that stakeholders pressure can influence the adoption of environmental logistics practices only through its efforts to build a unique environmental culture (Kim, S. T., \& Lee, S. Y. ,2012).

\section{Digital interaction on eco label chain return on experience}

Recalling sustainability development principles the challenge goes beyond enriching eco retailing digital interaction from content or diffusion, toward the co-creation of knowledge as resulted from purposely adopting business practices, driven by commitment features of responsible consumption.

Multiple perspectives of collaborative strategic thinking approach deepens the understanding of the role of co-creation of knowledge within the online communities of the European eco-label product industry (Capatina, Bleoju, Micu and Dragan, 2018 ).

Market Intelligence capabilities of the eco-label retailers in Romania informs about their limited capability to engage in fully exploit digital interactions as their strategies are based mainly on market research and reports. Nevertheless some features of sustainability lies with reporting and documenting: audits on customer perceptions, which play a vital role in supporting differentiation strategies; positioning strategies focus on raising consumer awareness of the benefits of eco-labeled products (Micu, A., Micu, A. E., Capatina, A., Cristache, N., \& Dragan, B. G., 2018).

\section{Conclusion and further research}

Generating testable solutions that guide the behavioral adjustment of online retail players involves equipping them with benchmarking systems against which they should assess their level of maturity to successfully engage in eco disruptive behavior.

Under these conditions, the Romanian retailers of eco-label products must not lose sight of the opportunities for strategic collaboration with the producers and customers, but they must also consider the creation of new partnerships that will lead to benefit from the enriching experiences of increasing consumption for eco-label products. The initiative of providing a platform for digital interaction advocates for eco label identity, informs about common values, purposes and value proposition, while providing the good practices of various stakeholders responsible production, distribution and consumption.

In order to discover new knowledge about future eco purchasing behaviour, future research has to engage in assessing cultural precursors of customer knowledge based interaction in order to deliver upon eco label competitive identity. The long term approach supposes to confront resistance to change when it comes to prove the match of value based competition and eco labelling identity, in order to influence a common vision among stakeholders of on line retailing business. The short term approach articulates the following three components:

1. Applied research to recognize barriers and enablers of engaging in eco behaviour driven by various incentives; training with good practices of digital marketing proficiency on eco retailing

2. Setting up a platform for experimenting scenarios to leverage eco-label competitive identity with capitalizing upon proficiency in Digital marketing

3. Developing eco labeling based culture to provide customer knowledge interaction to anticipate eco purchasing behaviour on future markets.

Acknowledgements: This research was supported by an internal grant of "Dunarea de Jos" University of Galati (GI 06/01.03.2019) 


\section{References}

1. Battistella, C., Annarelli, A., \& Nonino, F. (2015, September). Exploring the Impact of Organizational and Working Models, Incentives and Collaboration Strategies on Innovation Development in Online Communities of Practices. In European Conference on Knowledge Management (p. 112). Academic Conferences International Limited.

2. Bleoju G., Dragan B.G., Capatina A. (2018), Green leadership trust builder influencing eco-oriented corporate culture, 5th International Scientific Conference New trends in management and production engineering- regional, cross-border and global perspectives, Brenna, 7th - 8th June 2018, Poland, http:/ / www.wsb.edu.pl/ conference-program-new-trends-in-management-and-production-

engineering, m, conf,3390

3. Capatina, A. Bleoju, G. Micu, A. and Dragan B. G.: The Role of an Eco-Knowledge Hub in Leveraging Intellectual Capital Green Governance in cartea: Intellectual Capital Management as a Driver of Sustainability - Perspectives for Organizations and Society, Editors: Matos, F., Vairinhos, V., Selig, P.M., Edvinsson, L. (Eds.), SPRINGER, https:// wnw.springer.com/us/book/9783319790503

4. Capatina, A., Bleoju G. (2012, September). Organisational Instructional Communication as a Cultural Based Competitive Intelligence Tool, Proceedings of the 13th European Conference on Knowledge Management; Universidad Politécnica de Cartagena, Spain

5. Chen, I. Y., \& Chen, N. S. (2009). Examining the factors influencing participants' knowledge sharing behavior in virtual learning communities. Journal of Educational Technology \& Society, 12(1), 134.

6. Cheng, J. L. (2007). Critical issues in international management research: an agenda for future advancement. European Journal of International Management, 1(1-2), 23-38.

7. Desmet, D., Markovitch, S., \& Paquette, C. (2015). Speed and scale: Unlocking digital value in customer journeys. McKinsey Insights and

Publications:http:// mmw.mckinsey.com/insights/operations/speed_and_scale_unlocking_digital_value_in_c ustomer_journeys

8. Dornbusch, F., \& Brenner, T. (2013). Universities as local knowledge hubs under different technology regimes-New evidence from academic patenting (No. 10.13). Working Papers on Innovation and Space.

9. Gatignon, H., Lecocq, X., Pawwels, K. et al. A marketing perspective on business models, AMS Rev (2017) 7: 85. https:// doi.org/10.1007/s13162-017-0108-5, bttps:/ / link.springer.com/ article/10.1007/s13162-017-0108-5\#citeas

10. Gerbard Fischer. 2017. Exploring design trade-offs for quality of life in buman-centered design. $<$ em>Interactions </em> 25, 1 (December 2017), 26-33. DOI: https:// doi.org/10.1145/3170706

11. Goertz, Gary, and James Mahoney. 2012. A Tale of Two Cultures: Qualitative and Quantitative Research in the Social Sciences.Princeton and Oxford: Princeton University Press.

12. Graça, P., \& Camarinha-Matos, L. M. (2017). Performance indicators for collaborative business ecosystems —Literature review and trends. Technological Forecasting and Social Change, 116, 237-255.

13. bttps:// wnw.mckinsey.com/ business-functions/strategy-and-corporate-finance/our-insights/debiasing-thecorporation-an-interview-with-nobel-laureate-richard-thaler, Accessed May 2018

14. Javetski, Bill and Koller Tim: Debiasing the corporation: An interview with Nobel laureate Richard Thaler, InterviewMcKinsey Quarterly, May 2018

15. Kim, S. T., \& Lee, S. Y. (2012). Stakeholder pressure and the adoption of environmental logistics practices: is eco-oriented culture a missing link?. The International Journal of Logistics Management, 23(2), 238-258.

16. Linnenluecke, M.K., Verreynne, M.L., de Villiers Scheepers, M.J., Venter, C., 2017. A review of collaborative planning approaches for transformative change towards a sustainable future. Journal of Cleaner Production, 142.

17. Micu, A., Micu, A. E., Capatina, A., Cristache, N., \& Dragan, B. G. (2018). Market Intelligence Precursors for the Entrepreneurial Resilience Approach: The Case of the Romanian Eco-Label Product Retailers. Sustainability, 10(1), 190.

18. Muñoz, R. M., Pablo, J. D. S. D., \& Peña, I. (2015). Linking corporate social responsibility and financial performance in Spanish firms. European Journal of International Management, 9(3), 368-383.

19. Owen, G. (2014). University Knowledge Hubs and Economic Growth, Retrieved from https:// smartech.gatech.edu/handle/1853/51695 
20. Schoemaker, P. J. (1993). Strategic decisions in organizations: rational and behavioural views. Journal of Management Studies, 30(1), 107-129.

21. Stanciu S., Dragan B. G., Florea A, Bichescu C. (2018), Enablers and inbibitors of collaborative network development in organic food industry: A furzy set qualitative comparative analysis (fsQCA), Contemporary Economics, December 2018

22. Toni, M., Renzi, M. F., \& Mattia, G. (2018). Understanding the link between collaborative economy and sustainable behaviour: An empirical investigation. Journal of Cleaner Production, 172, 4467-4477.

23. Van Bommel, E. (2011), Artificial Intelligence Driving the Fourth Industrial Revolution Retrieved from bttp:/ / wmw.ipsoft.com/ artificial-intelligence-driving-the-fourth-industrial-revolution/

24. Wang, C., \& Hu, Q. (2017). Knowledge sharing in supply chain networks: Effects of collaborative innovation activities and capability on innovation performance. Technovation 